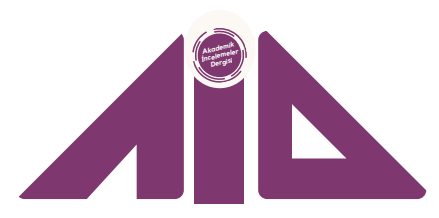

\title{
Etik Kültürünün Geliștirilmesinde Sivil Toplumun Rolü
}

The Role of Civil Society in Improving Ethical Culture

\author{
Fatih ALTUN \\ Dr. Öğr. Üyesi, Bandırma Onyedi Eylül Üniversitesi, \\ Sağlık Hizmetleri Meslek Yüksekokulu, Sosyal Hizmet ve Danıșmanlık Bölümü \\ fatihaltun75@gmail.com \\ https://orcid.org/0000-0001-5464-0909 \\ Hürü AKALIN \\ Yüksek Lisans Öğrencisi, Bandırma Onyedi Eylül Üniversitesi, \\ Sağlık Bilimleri Enstitüsü, Sosyal Hizmet Anabilim Dalı \\ huruakalin95@gmail.com \\ https://orcid.org/0000-0001-6017-5505
}

\section{Araștırma \& Yayın Etiği \\ Bu makale en az iki hakem tarafindan incelenmiș, iThenticate yazılımı ile taranmış, \\ araștırma yayın ve etiğine aykıııık tespit edilmemiștir.}

\section{BY-NC 4.0}

Bu makale Creative Commons Attribution-NonCommercial License altında lisanslanmıștır.

This paper is licensed under a Creative Commons Attribution-NonCommercial License

\section{Research \& Publication Ethics}

This article was reviewed by at least two referees, a similarity report was obtained using iThenticate, and compliance with research/publication ethics was confirmed.

\section{Copyright $\odot$}

Sakarya Üniversitesi, Sosyal Bilimler Enstitüsü, Sakarya/TÜRKIYE

Sakarya University, Institute of Social Science, Sakarya/TURKEY

\section{Atıf/Citation}

Altun, Fatih , Akalın, Hürü . "Etik Kültürünün Geliștirilmesinde Sivil Toplumun Rolü". Akademik incelemeler Dergisi 16 / 1 (Nisan 2021): 212-229. https://doi.org/10.17550/akademikincelemeler.860683

Makale Türü/Article Type: Araştırma Makalesi/Research Article

Geliş Tarihi/Date Received: 13.01.2021

Kabul Tarihi/Date Accepted: 10.04.2021

Yayın Tarihi/Date Published: 15.04.2021

ISSN: $\quad 1306-7885$

E-ISSN: $2602-3016$ 


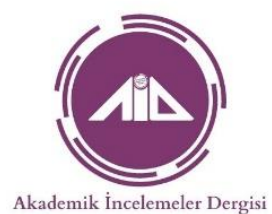

\title{
Etik Kültürünün Geliştirilmesinde Sivil Toplumun Rolü
}

\section{Öz}

Etik, bireylerin toplumsal hayatta gerçekleştirdiği davranışları doğru-yanlış, iyi-kötü çerçevesinde sınırlandırmaktadır. Bu bağlamda toplumsal hayatta bireylerce etik ilkelere uygun davranışların geliștirilmesi tüm toplumun huzuru için gereklidir. Kamu ve özel sektör kurum ve kurulușları nezdinde etiğe aykırı davranıșların denetlenmesini sağlayan mekanizmalar bulunmaktadır. Tüm bu mekanizmaların yanına da özel sektörden ve devletten bağımsız olarak var olan sivil bir alan bulunmaktadır. Bu sivil alanın ögesi olan sivil toplum örgütleri, üçüncü bir sektör olarak, toplumun her kesiminden bireyleri gönüllülük esası ile bünyesinde barındıran bir yapıya sahiptir. Yaptıkları çalışmalarla toplumda insanların yaşam kalitelerinin artmasına katkı sağlamayı, etik faktörlere ve değerlere saygıyı geliștirmeyi hedeflemektedirler. Kamu ve özel sektöre yönelik denetim rolü de olan sivil toplum örgütleri toplumsal hayatta etik ihlallere karşı bir ses konumdadır. Etik ihlallere karşı bilincin oluşması ve etik davranışların toplum geneline yayılmasıyla kültürel olarak bireylerin etik davranışları içselleştirmesi sivil toplum örgütleri aracılığıyla gerçekleşmektedir. Bu bağlamda çalışmanın amacı etik kültürünün oluşmasında sivil toplumun rolünü incelemektir. Çalışmada öncelikle etik ve etik kültür kavramı, daha sonra sivil toplum ve sivil toplum kuruluşları ve son olarak da etik kültürün geliştirilmesinde sivil toplumun rolü literatür üzerinden ele alınmıştır. Yapılan değerlendirmelerde; kamu ve özel sektörden bağımsız üçüncü bir sektör olarak nitelendirilen sivil toplum alanı, toplumun genelinde bireyler özelinde ortaya çıkan etik ihlallere karşı bir bariyer görevi gördügü ve etik kültürünün oluşturulmasında aktif bir rol oynadığı görülmüştür. Sonuç olarak; sivil toplum örgütlerinin toplum üzerindeki dönüştürücü rolü, etik olan davranışlarını toplumsal hayatta bireylere kazandırmasında önemli bir rol oynadığı söylenebilmektedir.

Anahtar Kelimeler: Etik Kültür, Sivil Toplum, Sivil Toplum Örgütleri

\section{The Role of Civil Society in Improving Ethical Culture}

\begin{abstract}
Ethics limits the behavior of individuals in social life within the framework of right-wrong, good-bad. In this context, the peace of the whole society must develop behaviors by ethical principles by individuals in social life. There are mechanisms for auditing unethical behaviors before the public and private sector institutions and organizations. In addition to all these mechanisms, there is a civilian area that exists independently of the private sector and the state. As a third sector, nongovernmental organizations, which are an element of this civil field, have a structure that includes individuals from all segments of society voluntarily. They aim to contribute to the increase in the quality of life of people in society with their work and to develop respect for ethical factors and Values. Non-governmental organizations, which also have an audit role for the public and private sectors, are in a voice against ethical violations in social life. With the formation of awareness against ethical violations and the dissemination of ethical behaviors throughout the society, individuals culturally internalize ethical behaviors are realized through non-governmental organizations. In this context, the aim of this study is to examine the role of civil society in the formation of ethical culture. In the study, firstly the concept of ethical and ethical culture, then civil society and non-governmental organizations, and finally the role of civil society in the development of ethical culture were discussed through the literature. In the evaluations made, it was seen that the civil society area, which is defined as a third sector independent from the public and private sectors, acts as a barrier against ethical violations that occur in the general society and plays an active role in the creation of an ethical culture. As a result, it can be said that the transformative role of non-governmental organizations on society plays an important role in bringing their ethical behaviors to individuals in social life.
\end{abstract}

Keywords: Ethical Culture, Civil Society, Non-Governmental Organizations 


\section{Giriş}

Toplumsal hayatta bireyler her zaman için doğru-yanlış, iyi-kötü ayrımını yapmak istemişlerdir. İnsanların bu arayışı karşımıza etik kavramını çıkarmaktadır. Etik kavramı, bireyin toplumsal hayatta gerçekleştirdiği ve çevresinde yaşayan insanları da etkileyen sonuçları bulunan, davranışları ve eylemleri düşünme süreçlerini ifade etmektedir. $\mathrm{Bu}$ bağlamda etiği üç biçimde ele almak mümkündür. Birincisi; felsefenin bir alanı olarak, iyinin ne olduğunu ve insanların ideal davranışlarının neler olduğunu çözümlemektir. İkincisi; toplumun genelinde insanların iletişim halinde olduğu düzlemde, nelerden kaçınmaları ya da neleri yapmaları gerektiğine çerçeve kazandırmaktır. Üçüncüsü ise, profesyonel anlamda bir mesleği icra eden bireylerin uyması gereken kuralları ifade eden mesleki etik uygulamalardır (Yıldırım ve Kadığlu, 2007, 76). Bir bireyin etik karar vermesi; davranışı meydana getirecek yolları ve davranışın sonuçlarını düşünerek kendi değerlendirme sürecinden geçirerek seçim yapmasıdır (Özdemir, 2009, 132). Bireyin etik karar vermesi süreci; adalet, haklar, dürüstlük ve hakkaniyet ilkelerini göz önünde bulundurmasını da içermektedir (Kıranlı ve İlğan, 2007, 150). Etik davranışın özünde; insanların seçimlerimize saygı duymasını istediğimiz gibi başkalarının da seçimlerine saygı duymak, insan haklarının göz önünde bulundurulmasına duyarlı olmak ve farklılıklara saygı gibi her bireyi ilgilendiren ve her bireyin davranışlarını gerçekleştirirken göz önünde bulundurması gereken temel noktalar mevcuttur. İnsanların davranışlarını etik ilkelere göre gerçekleştirmesi, zaman zaman kişisel çıkarlar ve kişisel düşünceler çerçevesinde sekteye uğrayabilmektedir. Bu bağlamda toplumsal hayatta farklı alanlarda etik ihlaller artabilmektedir. Bu nedenle toplumsal hayatta ortaya çıkan etik ihlallere dikkat çekilmesi ve bu ihlallerin geniş bir kamuoyuna duyurulmasında sivil toplum örgütleri önemli bir işleve sahiptir.

Sivil toplum; otoritenin karşısında yer alan, özerk bir yapısı bulunan, gönüllü örgütlenmelerden oluşan ve devlete hukuki zeminde bağlı olmanın dişında herhangi bir bağımlılığı olmayan bir alandır (Keser ve Hışım, 2016, 220). Bu tanımdan da anlaşılacağı üzere aslında sivil toplum kavramı halkın kendisini ifade etmektedir. Halk bir taraftan örgütlenmelerle otoritenin almış olduğu kararları sorgularken diğer bir yönden toplumsal hayatta var olan ihlaller ve sorunlar karşısında sesini çıkarmaktadır. Otoriteyi denetleme görevi demokrasinin sağlanmasıyla ilgiliyken, toplumsal hayatı düzenleyici bir rolünün varlı̆̆ı da gözden kaçırılmamalıdır. Toplumsal hayatı düzenleyici görevi, etik kuralların yerleşmesine katkı sunmaktadir.

Literatüre bakıldığında, etik ve sivil toplum kavramları üzerine ayrı ayrı çalışmaların bulunduğu görülmektedir. Özellikle etiğin sağlanması üzerine daha çok kamuda bulunan uygulamalardaki etik aksaklıklar üzerine durulmaktadır (Çevikbaş, 2006; Özdemir, 2008; Kaplan,2009; Bozkurt, 2010; Gökçelik, 2010; Koçak ve Yüksel, 2010; Yaman, 2010; Usta, 2011; Eryılmaz ve Biricikoğlu, 2011; Yıldız Özsalmanlı ve Pank, 2013; Önen ve Yıldırım, 2014; Özgür, 2016; Uzun, 2017; Uzun, 2018; Uzun, 2019; Kayacı, 2019; Aydın ve Demirtaş, 2020; Özkal Sayan, 2020). $\mathrm{Bu}$ noktada etik kültür ve sivil toplum ilişkisini değinen bir çalışmaya rastlanılamaması, bu çalışmanın özgünlüğünü ifade etmektedir. Çalışmanın amacı ise etik kavramını irdeleyerek, etik kültürün oluşmasında sivil toplumun sahip olduğu işlevleri belirtmektedir. Çalışmada sırasıyla; etik ve etik kültür kavramı, sivil toplum ve sivil toplum kuruluşları ve son olarak da etik kültürün geliștirilmesinde sivil toplumun rolüne değinilmiștir. 


\section{Etik Kavramı}

Etik kavramı, kökeni itibarıyla "ethos" sözcüğünden türetilmiştir. İnsanların birbirleri ile kurdukları ilişkilerin ahlaki açıdan iyi-kötü ve doğru-yanlış ayırımına işaret etmektedir (Akdoğan, 2003, 6). Türk Dil Kurumu Sözlügü'ne göre ise "töre bilimi, çeşitli meslek kolları arasında tarafların uyması veya kaçınması gereken davranışlar bütünü” anlamına gelmektedir (TDK, 2020). Kuçuradi (2001) etiği, bireylerin birbirlerine karşı sergiledikleri tutum ve davranışlara odaklanan bir felsefe alanı olarak ifade etmiştir. Diğer taraftan, sosyal yaşamda kendine özgü değer ve normları oluşturduğuna dikkate çekmektedir (Kuçuradi $(2001,16)$. Bu yönüyle etik, bireylerin gerçekleştirmiş oldukları eylemleri ve bu eylemleri sınırlayan normları araştırmaktadır. Bireyin diğer insanlarla nasıl yaşayacağı üzerine bir düşünme eylemidir (Usta, 2011, 40). Bireylerin toplumsal hayatta doğru-yanlış, ödev-yükümlülük ve toplumsal sorumluluk kavramları üzerine düşünmesine olanak sağlamaktadır (Gökçe ve Örseli, 2011, 48).

Bilimsel bir çerçevede felsefe alanı olan etik, sadece düşünsel anlamda değil uygulama alanında da kendisini göstermektedir. Bu anlamda bir bilim alanı olarak, insan toplulukları ve her birey için genel geçer kabul edilen kuralları ifade etmektedir (Özlem, 1997, 336). Özü itibariyle etik, bireye sosyal hayatta rehber konumundadır (Taner ve Elgün, 2015, 100). Rehberlik ederken ise bireyin her türlü faaliyeti kapsam içerisinde değildir. Etiğin odağı ahlaki eylemler olmaktadır. Pieper (1999) etiği, hayatta yönümüzü bulmamıza yarayan pusulaya benzetmektedir. Pusula ile etiğin aynı işleve sahip olduğunu, etiğin de pusula gibi bireyi doğru kabul edilen davranışları yapmasına yardımcı olduğunu belirtmektedir (Pieper, 1999, 29).

Etik sözcügünün genel anlamda iki farklı kullanımının olduğundan söz edilebilir. Birinci kullanımı; davranışta bulunan kişinin, yapması istenen eylemleri sorgulayarak, düşünerek toplumsal yaşamda beklenilen iyiyi gerçekleştiren ve bu gerçekleştirme eylemini süreğen hale getirmek anlamına gelmektedir. Alışkanlık haline getirme eylemini karakter kavramı karşılamaktadır ve süreğen bir şekilde erdemli olma vurgusu bulunmaktadır. İkinci kullanımda ise "alışkanlık, töre görenek" anlamlarını ifade ederek, töreye ve geleneklere uygun davranarak ve ahlak yasasını göz gönünde bulundurarak davranış sergilediğinde, etiğin gerektirdiği gibi davranış gerçekleştirilmiş olmaktadır (Uzun, 2009, 19). Etiğin temel çerçevesi toplumun bireyden beklemiş olduğu ahlaki davranışların özünü araștırarak, "iyi olan nedir?" ve "iyi olmak için ne yapmalıyız?" gibi sorulara cevap bulma çabası vardır (Elçi ve Alpkan, 2006, 143). Etik, bireye neyin yapılması gerektiği yolunu çizerken neyin yapılamayacağı noktasında da yol göstermektedir (Kırel, 2000, 2). İnsanlarda kendi çıkarlarına odaklanmış bir davranış söz konusu değilse yaşadığı çevredeki bireylere karşı göz önünde bulundurduğu yükümlülüklere ilişkin etik bir bakış açısı bulunmaktadır. Bu noktada bireyden beklenen, çıkarları ile etik davranış gerçekleştirme arasında bir denge sağlamasıdır (Fukuyama, 2005, 57). Bireyin gerçekleştirmiş olduğu davranış eğer ki insanlara zararlı etkiler bırakıyor ise ve toplumda hâkim olan genel ahlak kurallarına ters ise etik olmayan davranış olarak nitelendirilmektedir (Töre, 2006, 15). Diğer bir deyişle, bireyin kendi inançları ve toplumda var olan normlar tarafından kötü ve yanlış olarak nitelendirilen davranış söz konusudur. Etik, bireyin davranışlarını şekillendirdiği gibi, toplumda var olan örgütlerin ve toplumsal hayatın işleyişine de etki etmektedir. Bu yönüyle etiğin farklı yönlerinden söz edilebilir. Bireysel boyutta; etik ilkelerin uygulanması, birey 
merkezli oluşunu göstermektedir. Mikro boyutta; bireyin etik ilkeleri davranışlarına uygulaması, bireysel boyutu ön plana çıkarmaktadır.

Toplumda aynı amaca hizmet etmek amacıyla bir araya gelen kişilerin aynı davranışları gerçekleștirmesi örgütsel boyuta işaret etmektedir. Aynı amaca hizmet etmek gayesinde olan bireylerin ortak davranışları gerçekleştirmek istemeleri etik ilkelerin örgütlerce uygulanması gerekliliğini ortaya koymaktadır. Etiğin toplumsal boyutunda ise insanların toplumsal hayatta uyumlu bir şekilde yaşaması ve toplumda bir uzlaşının sağlanması vardır (Gül, 2008, 3). Bu bağlamda etik her boyutu ile toplumsal yaşamı düzenlemektedir. Etik davranışların toplumsal hayatta tüm bireyler tarafından benimsenerek uygulanması, toplumda var olan kültürün etik davranışları benimsemesi ile mümkündür.

\section{Kültür ve Etik Kültürü}

Kültür; toplumun ortak paydasını ifade eden, toplumdaki bireylerin davranışlarına yansıyan ve yayılan, toplumun genelinin kabul etmiş olduğu değerleri ve algıları ifade etmektedir (Sarıoğlu, 2008, 103). Bir diğer ifade ile kültür, bireyden bireye aktarılan yaşam biçimi olarak ele alınabilir. Bireyin sosyal yaşantısında edinmiş olduğu her algıyı, değer ölçülerini, alışkanlıklarını ve zihniyetini içermektedir. Bu sebepledir ki, kültür, bir toplumu diğer toplumdan farklı kılmaktadır (Kınay, 2006, 19). Kültür özellikleri bakımından somut ve soyut niteliği ifade etmektedir. Bireyin toplumsal hayatta sahip olduğu bütün araç ve gereçler somut kültürü, birey için çevresindeki olay ya da durumlara yüklediği anlamlar ve değerler ise soyut kültürü ifade etmektedir (Sabuncuoğlu ve Tüz, 1998, 33).

Hofstede kültürü; farklı toplumları birbirinden ayırt etmeye yarayan zihinsel bir programlama olarak tanımlamaktadır. Programlama ilk olarak ailede başlamakta ve içinde bulunulan okul, arkadaş çevresi, çalışma ortamı gibi ortamlardan beslenerek yaşanılan toplumda şekillenmektedir. Hofstede'e göre kültür; öğrenme ile oluşmakta ve bu öğrenmede sosyal ortam etkili olmaktadır (Hofstede, 1980, 4). Kültür, gelenek-görenek anlamında "ferdin izlemesi gereken ahlaki ölçütler" olarak ele alınırken; etik ise davranış kuralları niteliğinde "fertlerin doğru şekilde nasıl hareket edeceğini tarif eden ve açıklayan prensipler, değerler bütünü" olarak tarif edilebilir (Görmez vd., 2009, 298). Bu tanımlamadan da hareketle, kültürle etiğin birbirini destekler bir bağlantısının olduğu anlaşılmaktadır. Davranışları şekillendiren etik kurallar, kültürün unsurlarıdır. Çünkü kültür ve etik; birbirlerinin karşılıklı olarak oluşmasında ve biçimlenmesinde doğrudan etki sahibidir. Etik ilkeler; evrensel değerlerden beslenerek tutum ve amaçları açıklayan, alınan kararların bunlara uygunluğu için rehberlik eden kültürel yapı taşlarıdır (Uluğ, $2009,7)$. Dolayısıyla ilke ve değerler sistemi uzun zamanlı birikimler şeklinde oluşur; toplumsal ve örgütsel süreçler vasitasıyla benimsenebilir olduğunu söyleyerek kültürün, tutumları tarif etmede ahlaki şifreleri içeren bir kaynak olduğu belirtilebilir. $\mathrm{Bu}$ açlklamalardan hareketle de etik mefhumunun, insanın hangi eylemlerinin iyi hangilerinin de kötü olduğu ile ne şekilde davranması gerektiği hususunda parolaları içerdiği ifade edilebilir (Ay, 2005, 32). Etik kodların ögeleri incelendiğinde; bu kodların fertlere ödev ve sorumluluk yüklediği, bireyin vicdanında iyi niyeti meydana getirdiği ve etik bakımından kendini kontrol etme konusunda tesir ettiği; hatta insan tutumlarında iyi, doğru, fedakârlık ve onur olarak vurgulanabilecek yönlendirici nitelikler taşıdığı görülmektedir (Cevizci, 2002, 7). Bu kodların ortaya çıkması, fertlerin içinde yaşadığı toplumla ve o toplumun kültürüyle doğrudan bağlantılıdır. 
Kültür ise, fertlere kalıtım yoluyla aktarılmadığı veya doğada hazır bulunmadığı, dolayısıyla da toplum-insan ilişkisinde pozitif-negatif ve maddi-manevi her şeyin genel adıdır ve de bireylerin birbirleriyle ve tabiatın diğer unsurlarıla olan münasebetlerini incelemektedir (Pehlivan, 1998, 8-9). Dolayısıyla etik davranışların/tutumların, her zaman kültürle iç içe olduğu belirtilebilir. Diğer bir söylemle kültür; soyut niteliğiyle bireylerin duyum, kavrama, akıl ve davranma süreçlerini biçimlendirerek kişisel, toplumsal ve örgütsel kültür açıdan etiğe uygun davranışlara tesir etmektedir. Dolayısıyla bu açıdan etik; kültürün alt bir boyutu olarak görülebilmektedir (Görmez vd., 2009, 298). Dolayısıyla etik ilkeler; genel anlamda kültürel değerlerden esinlenen, kurumsal ve toplumsal yapı içerisinde çalışanların davranış şeklini ve amaçlarını belirleyen ya da açıklayan, aldıkları kararların uygunluğu için rehberlik eden kültürel yapı taşlarıdır. Kültürler birbirleriyle sürekli ilişkili olduğundan aralarında net bir ayrım belirlemek zordur. Tüm bunlardan çıkarımla da genel anlamda etik kültürü içeren; değer, ilke ve kültür yapısı uzun zamanlı birikim ve kazanımla ortaya konabilmektedir. Sonrasında ise toplumsal ve örgütsel süreçler vasıtasıyla benimsetilebilir (Uluğ, 2009, 7). Bireyin ortaya koyduğu davranışının etiğe uygunluğu sadece bireyin kişisel etik ve değerleri aracılığıyla değil, toplumun genel kanısı çerçevesinde şekillenmektedir. Bir diğer deyişle; ortam ve toplumsal bakış etik uygunluk üzerinde etkilidir

Kültür; öğrenilebilen bilgi, davranış ve alışkanlıkları barındırdığı için etik kurallar ve standartlar da aynı oranda kültür içerisinde öğrenilebilme ve uygulanabilmeye olanak bulmaktadır. Kültürel ögeler ve etik ilkeleri birlikte değerlendirecek olursak, nesiller boyu aktarılabilen bir özelliği barındırmaktadır. Önemli olan bireylerin kültürlerinde etik ilkeleri benimsemesidir. Kültür toplumdan topluma farklılık göstermektedir fakat etik ilkeler evrensel bir niteliğe sahiptir. Günümüzde var olan teknolojik gelişmelerle ortaya çıkan küreselleşme ile bireyler arasında ortak bir bilinç oluşması durumu söz konusudur. Geniş bir perspektiften düşündüğümüzde, küreselleşme dünyada oluşacak ortak bir bilinç ve değerler yargısının oluşmasına imkân oluşturmaktadır (Akdemir, 2004, 48). Bu yönüyle kültür kavramının daha çok yerel kaynaklı, fakat etik kavramının evrensel olduğu düşünülse de aslında günümüz toplum yapısında bu küreselleşme ile birlikte toplumsal hayatta etik bir kültür yapısının oluşması mümkün hale gelmektedir. Bütün toplumların, bünyelerinde kültürel farklılıkları barındırsalar da etik ilkelerde ortak paydayı paylaşmaları gerekmektedir.

Toplumsal hayatta etik değerlere göre davranış geliştirmek hemen olacak bir şey değildir. En temelde bu davranış, ailede başlayan ve bireyin yaşadığı çevreden etkilenerek şekillenen bir süreci barındırmaktadır. Tüm bu süreçte etik değerlere, bireyler tarafından içselleştirildiği ölçüde toplumsal hayatta ideal olana ulaşılacaktır (Kayacı, 2019, 66). Bu yönüyle de etik ilkeler ve standartlar noktasında ortak bir algıya sahip olan toplumlarda toplumsal bütünleşme büyük ölçüde sağlanacaktır. Toplumsal hayatta etik değerler göz önünde bulundurularak davranış geliştirilmesi, en özelde bireyin daha sonrasında ailesinin ve geniş ölçekte toplumdaki diğer bireylerin huzurunu sağlamada önemlidir. Mikro ölçekte birey, davranışlarını etik ilkelere uygun şekilde gerçekleştirir. Makro ölçekte ise davranışların toplum tarafından benimsenmesi ve uygulanması noktasında sivil toplum örgütlerinin büyük bir işlevi vardır. 


\section{Sivil Toplum}

Sivil toplumun ne ifade ettiğini anlamak için kavramın ne şekilde ortaya çıktığını bilmek yerinde olacaktır. Bu anlamda ilk olarak Aristoteles'in çalışmalarında ifade edilmiştir. 0 dönemde insanların yönetimi için gerekli olan usulün, şehir devleti olduğu belirtilmiştir. Devlet; insanların yönetilmesi için yasaların varlığı çerçevesinde özgür ve eşit yurttaşların siyasal toplumu şeklinde tanımlanmıştır (Onbaşı, 2003, 13). Devlet ile sivil toplum özdeş görülmektedir.

On sekizinci ve on dokuzuncu yüzyıla gelindiğinde sivil toplum kavramı ise yeni anlamlar kazanmaya başlamıştır. Keane'ye göre (1993, 49); temel olarak, sivil toplum anlayışı devletin var olmasını meşru kılmaya yönelik iken, devlet de sivil toplum bünyesinde bağımsız toplumlar var olmasına araç konumdadır. İkinci bir değișim olarak; sivil toplum ve devleti birbirinden ayrı olarak değerlendiren bir düşünce tarzı gelişmiştir. Üçüncü gelişme olarak; sivil toplum ve devlet ayrımında devlete karşı düşünce zayıflamaya başlamıştır. Üçüncü aşamaya tepki olarak ortaya çıkan gelişim ise, devletin elinde bulunan müdahalenin sivil toplumu yavaş yavaş etkisiz bırakacağı yönündedir (Keane, 1993, 49-52).

Sivil toplum kavramı üzerine birçok düşünür tanımlar ifade etmiştir. Tocqueville, toplum hayatının devamlılığı için toplumsal gücün bulunması gerektiğini vurgulamaktadır. Toplumda var olan gücün ise kontrol edilmesi gerektiğini ve bunun için sivil alana olan ihtiyacı ifade etmektedir. Sivil alanda var olan derneklerin ve örgütlerin bu denetim mekanizmasının ana faktörü olduğunu savunmaktadır. Sivil toplum örgütlerinin devletle bireyler arasında bir denge unsuru oluşturduğunu ve gönüllük esasıyla hep var olacağına dikkat çekmektedir (Tocqueville, 1994, 99). Benzer şekilde Rousseau da insanların güçlerini bir araya getirerek direniş oluşturabileceklerini ve bu şekilde meydana gelen bir sivil alanın varlığına işaret etmektedir. (Rousseau, 1999, 47). Hayek ise sivil toplumu ifade ederken, bireyin özgür oluşunu ve sınırlı devlet alanının varlığını vurgulamaktadır. Bireylerin sivil alandan güç alarak devleti sınırlayabileceğini ifade etmektedir (Hayek, 2014, 167). L. Diamond sivil toplumu; "gönüllülük esasında kendi kendini inşa eden ve aynı zamanda devamlılı̆̆ını sürdüren devlet sisteminden farklı yapı olarak çalışmalarını yürüten bir alan" olarak değerlendirmektedir (Diamond, 1994,5). Yine benzer şekilde White da sivil toplumu; "devletle özerk bir ilişkisi bulunan toplumda var olan gönüllü üyeleri çıkarlarını ve değerlerine uygun olarak çalışmalar yürütülen bir yapı" olarak tanımlamaktadır (White, 1994, 379).

İlk olarak Aristoteles'in çalışmalarında karşımıza çıkan, sivil toplum kavramı devlet ile aynı anlama sahiptir. Bu noktada sivil toplumun ortaya çıkışı tarihsel bir süreci kapsamaktadır. Bu tarihsel süreç içinde dört dönemden bahsetmek mümkündür. Her dönemde sivil toplum kavramının devletle ilişkisini görmek mümkündür. İlk dönemde; sivil toplumun devletle özdeşleşen anlamında bir değişim meydana gelmiştir. İkinci dönemin önemi; toplum içindeki grupların kendilerini devletten bağımsız bir noktaya konumlandırmalarıdır. Üçüncü dönem; sivil toplumun bir özgürlüğü içerdiği, toplumda olan çatışmaların önleyici gücün devlet olduğu düşünülen bir dönemdir. Son dönemde ise devletin sivil toplumu baskılarıyla boğacağından korkulmaya başlanmasını ifade etmektedir (Keane, 1993, 47- 48). Söz konusu aşamalardan geçen sivil toplum anlayışı her dönemde toplumsal hayatta kendine bir yer edinmiştir. Sivil toplum algısında yaşanan bu değişimlere bakıldığında ise, Türkiye'de Batı'daki anlayıșa benzer bir sivil toplumun varlığı tartışma konusu olabilmektedir. Türkiye'de kültürümüz ekseninde bir sivil toplum 
anlayıșı gelişme göstermiştir. Osmanlı ve Cumhuriyetin ilk yıllarında sivil topluma ilişkin çalışmaların olduğu görülmektedir. 1980'li yıllarla birlikte sivil toplum vurgusu ön plana çıkmaya başlamıştır. Günümüzde de demokrasinin sürekliliği için sivil toplumun gerekliliği vurgulanmaktadır (Gözübüyük, 2010, 103-104).

Tüm bu süreçlerin yanında günümüz toplumlarında var olan sivil toplum anlayışına bakacak olursak, sivil toplum demokrasi ile birlikte düşünülmektedir. Sivil toplumun nasıl daha fazla işlevsel hale gelebileceği düşünülürken demokrasinin gelişmesi ön plana çıkmaktadır. Bu noktada, sivil toplum devlete karşı bir kontrol mekanizması şeklinde değerlendirilmektedir (Gözübüyük, 2010, 91). Kontrol mekanizması açısından bakıldığında, sivil toplum ve demokrasi birbirini gerektiren bir ilişkiye sahiptir. Demokratik bir toplumda demokratik bir sivil toplumun oluşacağı kanısı vardır (Akpınar, 1997, 62). Demokrasinin var olmasında yönetici otorite olan devlet ile sivil toplumun birbiriyle ilişkisini kuran olgu ise katılımdır. Bu bağlamda sivil toplum, devlet ile birey arasında bir noktada konumlanmaktadır (Alp ve Adıgüzel, 2019, 38). Sivil toplumun varlığı; toplumsal yaşamda uzlaşının olduğu, toplumsal anlamda bir bütünlügün ve katılımın büyük ölçüde gerçekleștiği bir durumu ifade etmektedir.

Sivil toplum, merkezî otorite arasında bir alan olmasında iki işleviyle ön plana çıkmaktadır. Birincisi, toplumda hâkim olan siyasi otoritelerin vermiş oldukları kararlarda toplumun tepkilerini dile getirmesi, ikincisinde ise siyasi otoritenin uygulamış olduğu politikaların toplum tarafından benimsenmesi noktasında üstlendiği roldür (Arslan, 2001, 127). Bu nokta da sivil toplum mekanizması, toplumun sesi olduğu gibi devletin de sesi olma işlevine sahiptir. İki yönlü bir ilişkinin varlığından söz edilebilir. Bunun yanı sıra sivil toplum, toplumsal farklılaşmaya farklı fikirlerin hukuki zeminde tartışılmasına da olanak sağlamaktadır (Çaha, 2001, 45).

Toplumsal hayatta sivil toplum düşüncesinin var olabilmesi ve toplumda devletten bağımsız bir alanın oluşturulması için, ekonomik, siyasal ve kültürel olarak belli koşulların sağlanması gerekmektedir. Bunun için; Hukuk Devleti'nin varlığının yanı sıra devletin ekonomik, sosyal ve iktisadi faaliyetleri sırasında minimum düzeyde kendini göstermesi gerekmektedir. Adalet, güvenlik ve savunma faaliyetleri devletin tekelinde olmalı diğer alanlar ise sivil unsurların kontrolünde olmalıdır (Yıldırım, $2003,229)$. Bir diğer ifadeyle; toplumsal hayatta farklılıklara yer var ise, farklılıklar olmasına rağmen örgütlenmeler sağlanabiliyorsa, farklı fikirde olan bireyler gönüllü bir katılımla bir araya gelip aynı sorunlar için endişe duyuyor ise ve toplumda hayat bulan farklılıklar ve örgütlenmeler bir denetim mekanizmasına dönüşüyorsa sivil toplum düşüncesinden bahsedilebilmektedir.

Sivil toplumun işlevlerine değinecek olursak, otorite konumda olan iktidarı kontrol edebileceği bir mekanizmanın varlığı gerekmektedir. Vatandaş; katılım gücü ile neler yapabileceğini bilmeli ve demokratik davranışların geliștirilmesinde katkılar sunmalıdır. Toplumsal hayatta her zaman farklı fikirler var olmuştur ve var olmaya devam edecektir. Sivil toplum düşüncesi, zıt kutuplardakiler arasındaki birliktelik duygusunu geliştirme işlevini yerine getirmelidir (Ylldırım, 2003, 229). Tüm bu özellikler toplumun ilerlemesinde ekonomik ve sosyokültürel açıdan başat bir faktör konumundadır. 


\section{Sivil Toplumun Bir Ögesi Olarak Sivil Toplum Örgütleri}

Günümüzde sivil toplum kendinden çok daha fazla söz ettirmeye devam ederek göreceli de olsa yüksek bir sosyal etki gücünü elinde bulundurmaktadır. Bunun da yanı sıra toplumda destekleyici sosyoekonomik ve sosyopolitik ortamların varlığı ve özel sektör ile ilișkilerin olumlu yöne evrilmesi, gelişime açık bir toplum yapısını ifade etmektedir (Akmeșe, 2013, 220-221). Sivil toplumun düşüncesinin toplumsal hayatta yer bulmasının en önemli faktörünün sivil toplum örgütleri olduğu bir gerçektir.

Sivil toplum fikrinin toplumsal hayattaki yürütücüsü diyebileceğimiz sivil toplum örgütleri devletin dışında kalan alan olarak tanımlanmaktadır. Maddi bir kazanç kaygısında olmayarak gönüllülük esasıyla yürüttüğü faaliyetlerinde toplum yararı için çalışma amacı bulunmaktadır. Yaptıkları her faaliyette hiçbir dış otoritenin etkisi altında kalmama, devlet hiyerarşisi içinde yer almama ve siyasi oluşumların içerisinde bulunmama gibi özellikleri barındırmaktadırlar (Özden, 2008, 15). Sivil toplum kuruluşları devletten ayrılan sivil bir alan olmasına rağmen, hukuksal düzenlemelere uyarak toplumun ortak faydasını önceleyerek hareket ettikleri için ulusal ve uluslararası hukuk kurallarına bir aykırılık oluşturmamaktadır (Öner, 2001, 58-59). Bunun yanı sira sivil toplum kuruluşuna üye olan bireyler arasında eşit pozisyon olduğunu söylemek mümkündür. $\mathrm{Bu}$ eşitlik sivil toplum örgütlenmesini diğer örgütlenmelerden ayırmaktadır (Tekeli, 2000, 114). Bu eşitlik sayesinde bünyesinde bulunan üyeleri arasında her fikir rahatça tartışılıp üzerine yeni kararlar alınabilmektedir.

Sivil toplum kuruluşları, "hükümet dışı örgütler" olarak da nitelendirilmektedir. Ayrıca "üçüncü sektör, gönüllü kuruluşlar veya baskı grupları" şeklinde de ifade edilebilmektedir. Genel bir perspektiften bakıldığında ise, sivil toplum kuruluşları "belirlemiş oldukları alanlarda çalışmalar yapan ve otorite ile hukuki zemin dışında bir bă̆ı olmadan var olan her türlü örgütlenmeyi" ifade etmektedir. Dar perspektiften ise "sosyal ve ekonomik kalkınmaya dolaylı veya doğrudan katkı sağlamak hedefiyle gönüllülük, bağımsızlık, kâr amacı gütmemek ve toplum çıkarını ön plana alarak çalışma yapma esasında olan kuruluşlardır" (Velioğlu, 2009, 34). Toplumda ortaya çıkan bir sorunun çözümü için birlik ve dayanışma büyük önem arz etmektedir. Bu birlik ve dayanışma ruhu ile insanlar sivil toplum örgütleri aracılığıyla bir araya gelmektedirler. Belli bir sorun için bu noktada sivil toplum kuruluşları kamuoyu oluşturma işlevini yerine getirmektedir. Oluşan kamuoyu ile toplumda ortaya çıkan soruna karşı bir farkındalık oluşmakta ve böylece çözümler noktasında harekete geçme durumu gerçekleşmektedir (Özer, 2008, 92). Toplumsal hayatta sorunların çözümü için faaliyet yürüten sivil toplum örgütleri ortaya koymuş oldukları her faaliyette en büyük kuvveti toplumun sorunu için toplumun gücünü kullanmak olmuştur. Toplumda meydana gelen değişimlere göre; kaynakları harekete geçirerek, kitlelere ulaşmayı ve toplulukları bilinçlendirmeyi amaçlamaktadır (Marshall, 1999, 388). Özellikle, devletin eksik kaldığı noktada, bu noktaların ifade edilmesinde ve toplulukların örgütlenmesinde önemli rol oynamaktadır. Bu noktada toplumun bilinç düzeyinin artmasında, farklılıklara saygının gelişmesinde aktör bir konumdadır.

\section{Etik Kültürün Geliştirilmesinde Sivil Toplum}

Sivil toplum, toplumda meydana gelen değişimlere göre kaynakları harekete geçirerek, kitlelere ulaşmayı ve toplulukları bilinçlendirmeyi amaçlamaktadır 
(Marshall, 1999, 388). Özellikle, devletin eksik kaldığı noktada, bu noktaların ifade edilmesinde ve toplulukların örgütlenmesinde önemlidir. Bu noktada toplumun bilinç düzeyinin artmasında, farklılıklara saygının gelişmesinde aktör bir konumdadır.

Etik kültür ise, etik ilke ve davranışların toplumun kültürü tarafından benimsenerek toplum genelinde kabul görmesi şeklinde ifade edilebilir. Etik tutumlar her zaman toplumda hâkim olan kültürel yapıdan etkilenmektedir. Bu bağlamda bireyden beklenen etik davranış, bireyin sahip olduğu kültürel eylemleri ve inançları bünyesinde barındırmaktadır (Türegün, 2019, 103). Bireyin sosyal yaşantısına etik kuralların yerleşmesi için kültürel olarak etiği ne şekilde algıladığı göz önünde bulundurulmalıdır. Çünkü bir toplumun kültürel özellikleri dünyayı ne şekilde algıladığının bir sonucudur (İbrahimoğlu vd., 2014, 1117). Bu anlamda toplumda etik dışı olarak adlandırılan davranışlar bir anda ortaya çıkan bir durum değildir. Etik dışı davranışların ortaya çıktığı iklimi değerlendirmek, sistemsel olarak etik davranışları destekleyen kuralların varlığı ve bu kurallara karşı duyarlılığın arttırılması için çalışmak gereklidir (Eryılmaz, 2008, 9). Toplumsal yaşamda liyakate uygun davranılmaması, ișe alma ya da terfi etme gibi konularda veya diğer farklı kayırmacılık ve haksızlıklar, aktif hizmet veren kurumlarda ortaya çıkan yozlaşma ve yolsuzlukların oluşması tüm toplumun ahlaki ve etik değerlerini olumsuz etkilemektedir (Alper Ay ve Oktay, 2020, 157). Etik ihlallere karşı, "etik komitesi kurulu, etik görevlileri, ombudsman, etik eğitimi, sorun bildirme sistemleri, sosyal raporlama, diş denetim, etik ve sosyal denetim gibi yapıların oluşturulması gerektiği" ifade edilmektedir. (Küçükoğlu, 2012, 184). Her kurumda farklı uygulamalar olsa da kamu ve özel sektör kendi içerisinde etik konusunda denetim mekanizmaları oluşturmaktadır. Bunun yanı sıra kamu ve özel sektörün dişında üçüncü bir sektör olarak değerlendirilen sivil toplum alanı etik kültürün toplum geneline yayılması ve toplumda benimsenmesi için roller üstlenmektedir.

Bir toplumda otoritenin karşısında var olan sivil alanı ifade eden sivil toplumun yapısında, çoğulculuk bulunmaktadır (Tuncay, 2019, 55). Farklı düşüncelerin ve farklı kimliklerin varlığı bu alanın zenginliğini ifade etmektedir. Bu anlamda farklı düşünce ve kimlikler sivil toplum örgütlerini oluşturarak seslerini duyurmaktadır. Etik kültürün oluşturulmasında, bu çoğulcu yapı katkı sunmaktadır. Farklı fikirlerin toplumsal hayatta yer bulması yaşanan her olayın farklı açılardan irdelenebilmesine de olanak tanımaktadır. Sivil toplum yapısının bir ögesi olan sivil toplum kuruluşları ne alanda hizmet vermekte ise o alanda toplumsal bilinç oluşturmak için çalışmalar yürütmektedir. Etik davranışların toplumsal hayatta bir kabul görmesi ve kültür yapısına dönüşmesi için bu bilinç çalışmalarının katkısı oldukça mühimdir. Sivil toplum örgütleri ile insanlar ortak paydada bulușarak bir araya gelmektedir.

$\mathrm{Bu}$ noktada toplumda olası bir etik ihlalin yaşanması durumunda, insanlar sivil toplum örgütleri ile kamuoyuna seslerini duyurabilmektedirler. Bireyler sivil toplum örgütleri ile aracılığıyla etik ihlaller karşısında seslerini duyurarak kendi çıkarlarının ötesinde toplumun çıkarları için hareket etmiş olmaktadır. Ayrıca bir birey etik ihlaller konusunda tek başına sesini duyurmazken, sivil toplum örgütleri sayesinde daha güçlü ve sesini duyurabilir konuma gelmektedir.

Öte yandan, toplumsal yaşamda değişmelerin olmasıyla birlikte, ihtiyaçlar da değişmektedir ve devlet eliyle her şeye ulaşmak mümkün olamamaktadır. Bu noktada sivil toplum örgütleri, toplumsal hayatın içerisinde yer alan bireylerden oluşması sebebiyle devletin eksik ya da yetișemediği noktada büyük bir rol 
üstlenmektedir (Bulut vd., 2017, 31-32). Bu bağlamda sivil toplum örgütleri etik kültürün oluşması noktasında toplumda etiğin nasıl yer bulacağı konusunda politika yapıcılara yardımcı bir rol üstlenmektedir.

Bireyin kendi özelinde gerçekleştirdiği etik dışı davranış toplumun genelini etkilemektedir. Bu nedenledir ki, toplumda etik dışı davranışlara karşı sessiz kalmak huzursuz bir toplumsal hayatı kabullenmek demektir. Bu noktada bireylerin davranışlarını gerçekleştirirken, "benden bize, tekilden çoğula" şeklinde bir anlayış gerçekleştirmesi gerekmektedir. Sivil toplum örgütleri de bu anlayışın gerçekleşmesinde bir araç olmalıdır (Özler vd., 2010, 188). Sivil toplum örgütleri etik kuralların hayata geçirilmesinde örnekler oluşturacak bir konumu temsil etmektedirler.

\section{Sonuç}

Yerel oluşumlardan, bölgesel, ulusal ve hatta uluslararası düzeyde faaliyet gösteren sivil toplum kuruluşları toplumda ön plana çıkan taleplere yönelik faaliyetlerini şekillendirmektedir (Keijzer ve Bossuyt, 2020,788). Toplumda ortaya çıkacak etik ihlallerin önlenmesi noktasında da toplumun taleplerine ses olma konumunda bulunmaktadır. Aynı zamanda toplumsal yaşamda etik kültürün benimsenmesi adına yönetsel mekanizmalarla iş birliği içinde olma gibi olanakları vardır.

Sivil toplum örgütleri; bireylerin toplumsal hayatta yaşanan etik ihlallerin önüne geçmesine ve etik kültürün toplumsal yaşama yayılması için bireylerin -konuşup durmanın ötesine geçerek- açık yüreklilikle etik ihlalleri dillendirecek mekanizmalar kurarak etik anlayışın toplumsal hayatta benimsenmesine olanak sağlamaktadır (Öner ve Şen, 2020, 591). Böylelikle etik ilke ve değerlerin toplumsal hayatta benimsenmesi, sahiplenilmesi ve yaşamın her alanına yansıması toplumda birlik ve bütünlügün sağlanması noktasında iyileştirici olacaktır.

Toplumsal hayatın en küçük üyesinin birey olduğu düşünüldüğünde; birey, davranışlarını etik ilkelere uygun düzenler ise toplumun genelinde etik ilkelere uygun bir yaşama biçimi benimsenmiş olma ihtimali artacak ve toplumsal uzlaşı sağlanmış olacaktır. Mikro ölçekte bireyin davranışlarında etik uygunluk ararken, toplumdaki bireylere verilen hizmetleri oluşturan kamu ve özel sektör kurumlarının da aynı oranda hizmetlerinde etik ilke ve uygulamaları yerine getirmesi gerekmektedir. Özel ve kamu sektörünün kendi yönetim yapısında farklı uygulamalar bulunmaktadır. Ama kamu ve özel sektörden bağımsız üçüncü bir sektör olarak nitelendirilen sivil toplum alanı, tüm bunları denetleyen ve toplumun genelinde ve bireyler özelinde ortaya çıkan etik ihlallere karşı bir bariyer konumdadır.

Toplumsal hayatta sivil toplum bilincine sahip bireylerin örgütlenmesi sonucu oluşan sivil toplum örgütleri farklı görüşleri bünyesinde barındırarak toplumsal hayatta meydana gelen her olaya karşı eleştirel bir gözle yaklaşarak kamuoyu oluşmasında öncülük etmektedir (Özkul, 2017, 22). Bireylerin kendi düşünüş tarzına uygun bulduğu sivil toplum örgütlerince toplumsal hayattaki farklılıkları birey bazından örgüt bazına taşıyarak geniş kitlelere duyurulmasında etkili olmaktadır. Bu bağlamda etik ihlallerin ortaya çıkması durumunda, bunun geniş kitlelerce fark edilmesi ve çözüm yoluna gidilmesine dönük çalışmalarla toplumda yer alan etik kültürünün oluşmasında önemli bir faktör olarak karşımıza çıkmaktadır. 
Toplumsal hayatta sivil alanın aktörleri olarak adlandırabileceğimiz sivil toplum örgütleri toplumu sosyokültürel, bireysel ve iktisadi olarak birçok yönden etkilemekte ve şekillendirmektedir. Bu bağlamda sivil toplum örgütleri; toplumda bireylerin bireylere ve devlete karşı, devletin de aynı ölçüde bireylere karşı sorumlu olduğunu ortaya koymaktadır (Kanberoğlu ve Yıldırımçakar, 2019, 44-45). Toplumsal hayatta etik ilkelere uyulması ve etik ilkelerin toplumun geneline yayılması noktasında, bireylere ve devlete ait sorumlulukların ifade edilmesi noktasında çalışmalarını yürütmektedir. Toplumsal hayatta var olan etik sorunları netleștirmek ve bu alanda yapılması gerekenlerin denetlenmesi adına önemli bir işlevi yerine getirmektedir. Toplumda bireylerin sorunlarını dile getirerek sistemlerin doğru işlemesi adına çalışmalar yürütmektedir (Yeşildal, 2020, 41). Bu anlamda toplumda var olan sistemlerin, etik ilkelere uygunluğunu denetlemesi ve denetlenmesine yönelik girişimleri desteklemesi açısından sivil alanın varlığı önem arz etmektedir.

Sivil toplum düşüncesinin var oluşu toplumda var olan sorunlara yönelik taleplerin kitlelerce duyulması adına kimsenin söyleyemediğini söyleme, eleştirilemeyeni eleștirme ve bu yolla da bir denetim sağlama yönünü bünyesinde barındırmaktadır (Kutlu vd., 2021, 163). Bu yönüyle kamu kurumlarının topluma yönelik etik ihlallerine karşı, özel sektörün kendi bünyesinde yer alan çalışanlarına ya da topluma karşı bulunduğu etik ihlallerde eleştirel bir bakış açısıyla işbirliği içerisinde bulunması yönüyle toplumsal hayatta etik kültürün tüm alanlarda sağlanabilmesine olanak bulunmaktadır.

Sivil toplum örgütleri; kamusal alanda ortaya çıkabilecek etik ihlallerden doğrudan etkilenenin toplumun kendisi olmasından hareketle, toplumun zararına olabilecek/olan veya toplumun onaylamadığı eylemleri kamuoyu oluşturma işlevi ile engelleyebilmektedir. Sivil toplum devletin hiyerarşisinde yer almadan devleti belirli bir mesafeden izleyen bir yapılanmaya sahip olması nedeniyle olası etik ihlallerin dışında farklı bir perspektife sahiptir (Demir, 2018, 263). Küreselleșme ile birlikte çok kültürlü ve çok sesliliğin giderek arttığı günümüz toplumlarında, çok kültürlülüğün ve çok sesliliğin ortak paydasında etik ihlallere karşı birliktelik oluşturulması ve etiğin tüm toplumsal yaşamda dikkat edilen bir husus olmasında sivil toplum örgütleri önemli bir rol üstlenmektedir. Sivil toplum örgütleri; otoriteleri denetleyen bir konumda olmasının dişında, toplumun içerisinde sorunlara doğrudan maruz kalan bireylerden oluştuğu için bütün aksaklıkları bilen ayrıntılı değerlendirmeler yapabilen bir konumdadır. Bu yönüyle etik konusunda hem toplumdaki insanların hem de otoritelerin davranışlarını kontrol edebilmektedir. Etik anlayıșın kültürel olarak benimsenmesi bir anda olacak bir durum değildir. Bir süreci barındırmaktadır. Bu noktada, etik minvalinde sivil toplum örgütleri her geçen gün daha doğru olan davranışlarını toplumsal hayatta bireylere kazandırmak için uğraş vermelidir. 


\section{Kaynakça}

Akdemir, Müslim. Küreselleşme ve Kültürel Kimlik Sorunu. Sosyal Bilimler Dergisi, 3/1 (2004), 43-50.

Akdoğan, Habib. Muhasebe Meslek Etiğinin Kamunun Aydınlatılmasındaki Önemine Meslek Mensuplarının Yaklaşımlarl, Eskişehir: Anadolu Üniversitesi, Açıöŏğretim Fakültesi Yayınları, 2003.

Ay, Canan. İşletmelerde Etiksel Karar Almada Kültürün Rolü, Celal Bayar Üniversitesi Íktisadi ve Ídari Bilimler Fakültesi Yönetim ve Ekonomi Dergisi 12/2 (2005), 31-52.

Akpınar, Ayşenur. Sivil Toplum: Düşünsel Temelleri ve Türkiye Perspektifi. (Doktora Tezi). Ankara Üniversitesi Sosyal Bilimler Enstitüsü Kamu Hukuku Anabilim Dall, Ankara, 1997.

Akmeșe, Fatih. Sivil Toplum ve Türkiye Cumhuriyeti'ndeki Yeri, Hak-Iss Uluslararası Emek ve Toplum Dergisi, 2/4 (2013), 202-225

Ak, Bihter Güngör. Türkiye' nin Avrupa Birliği'ne Katılım Sürecinin Sivil Kuruluşlarına Etkileri ve Katkısı, II. Ulusal Sivil Toplum Kongresi Bildiriler Kitabı. Çanakkkale, 2005.

Alp, Ahmet - Adıgüzel, Vefa. Bir Barış Konsepti Olarak: Sivil Toplum ve Devlet İlişkisi, Sosyal Bilimler Akademi Dergisi, Özel Sayı (2019), 37-48.

Avrupa Komisyonu Türkiye Temsilciliği. Sivil Toplum İşbaşında, Ankara: Avrupa Komisyonu Türkiye Temsilciliği Yayını, 2001.

Arslan, Osman. Kurumsal ve Tarihsel Aşamalarıyla Sivil Toplum ve Türkiye Gerçeği, İstanbul: Bayrak Yayınları, 2001.

Aydın, Semra - Demirtaş, Fatma. Kamu Görevlileri Etik Sözleşmesi Maddelerinin Değerlendirilmesi (Odak Grup Çalışması), Uluslararası Liderlik Eğitimi Dergisi (ULED), I-1 (2020), 1-10.

Alper Ay, Ferda - Oktay, Semanur. Etik Çöküşe Yol Açan Nepotizm ve Uygulamalarının Örgütsel Güvene Etkisi: Bir Üniversite Hastanesinde Hekimler ve Hemşireler Üzerine Araştırma, İş Ahlakı Dergisi, 13/1 (2020), 135-168.

Bulut, Yakup vd., Kamu Politikalarının Oluşturulmasında Sivil Toplum Kuruluşlarının Etkisi, Strategic Public Management Journal, 3/6 (2017), 2338.

Bozkurt, Cevdet. Yolsuzlukla Mücadele Boyutuyla Etik ve Etik Kültürü, Denetişim,5 (2016), 44-53.

Cevizci, Ahmet. Etiğe Giriş, İstanbul: Paradigma Yayıncılık, (2002).

Çaha, Ömer. Türkiye' de Sivil Toplumun Oluşumu ve Gelişimi, Liberalizmin İncelenmesi, Ankara: Friedrich Naumann Vakfı Yayınları, (2001).

Çevikbaş, Refat. Yönetimde Etik ve Yozlaşma. Atatürk Üniversitesi İktisadi ve İdari Bilimler Dergisi,20/1 (2010), 265-289. 
Demir Alp, Konur. Toplumsal Uzlaşıda Devlet Yönetimi ile Toplum Arasındaki FrenDenge Unsuru: Sivil Toplum Yönetimi Üzerine Bir Değerlendirme, 8/1(2018), 247-271.

Diamond, Larry. Rethinking CivilSociety: Toward Democratic Consolidation. Journal of Demokracy, (1994).

Elçi, Meral - Alpkan, Lütfihak. Etik İklimin Örgütsel Vatandaşlık Davranışlarına Etkileri, Hacettepe Üniversitesi İ.I.B.F. Dergisi, 24/1 (2006), 141-170.

Eryılmaz, Bilal - Biricikoğlu, Hale. Kamu Yönetiminde Hesap Verebilirlik ve Etik, Iş̧ Ahlakı Dergisi, 4/7 (2011), 19-45.

Eryılmaz, Bilal. Etik Kültürü Geliştirmek, Türk Idare Dergisi,80/459 (2008), 1-13.

Fukuyama, Francis. Güven, Sosyal Erdemler ve Refahın Yaratılması (Çev: Ahmet Buğdaycı), İstanbul: Şefik Matbaası, (2005).

Gökçe, Orhan - Örseli, Erhan. Kamu Yönetiminde Etik ve Etik Dıșı Davranış Algısı. İş Ahlakı Dergisi, 4/7 (2011), 47-63.

Gökçelik, Özlem. Etik Kavramının Kamu Yönetimi ve İç Denetim Bağlamında Değerlendirilmesi, Denetişim,5 (2016), 54-63.

Görmez, Kemal. ve diğerleri. Etik, Kültür ve Toplum, (Ed. Ş. Korkusuz ve G. Keylan), Yolsuzluğun Önlenmesi İçin Etik Projesi Kamu Etiği Akademik Araştırmaları, Cilt 2,294-365. Ankara: KGEK, 2009.

Gözübüyük Tamer, Mine. Tarihsel Süreçte Sivil Toplum. Hacettepe Üniversitesi Edebiyat Fakültesi Dergisi, 2/1 (2010), 89-105.

Gül, Hasan - Gökçe, Hakan. Örgütsel Etik ve Bileșenleri, Süleyman Demirel Üniversitesi İktisadi ve İdari Bilimler Fakültesi Dergisi, 13/1 (2008), 377-389.

Güvenç, Bozkurt. İnsan ve Kültür. (9.Baskı). İstanbul: Remzi Kitabevi, 2002.

Haviland, A. William vd., (çev. İnan Deniz Erguvan Sarığlu). Kültürel Antropoloji. İstanbul: Kaknüs Yayınları, 2008.

Hayek, F. Kölelik yolu (Çev. T. Feyzioğlu vd.). Ankara: Liberte Yayınları,(2014).

Hofstede, Geert. Culture's Consequences: International Differences in Work Related Values, California: Sage Publication, 1980.

Kaplan, Çetin. Kamu Yönetiminde Etik ve Kamu Çalışanlarının Etik Kavramını Algllayışları, Süleyman Demirel Üniversitesi İktisadi ve İdari Bilimler Fakültesi Dergisi, 14/3 (2009), 343-355.

Kayacı, Müslüm. Kamu Yönetiminde Etik Bağlamında Güvenlik Hizmetleri Etiğine Bir Bakıș, Sosyal Bilimler Akademi Dergisi, 2/1 (2019), 50-69.

Kanberoğlu,Zafer - Yıldırımçakar, İsmail.Sosyo-Ekonomik Kalkınmada Sivil Toplum Kuruluşlarının Önemi,Van Yüzüncü Yıl Üniversitesi İktisadi ve İdari Bilimler Fakültesi Dergisi,4/7 (2019),30-47.

Keane, John. Sivil Toplum ve Devlet, İstanbul: Ayrıntı Yayınları, (1993).

Keser, Hayri \& Hıșım, Selin. Demokrasilerde Sivil Toplumun Rolü, İnönü Üniversitesi Hukuk Fakültesi Dergisi, 7/2 (2016), 201-224. 
Keyman, E. Fuat., İçduygu, Ahmet. Citizenship İn A Global World European Questions and Turkish Experiences, London: Routledge, 2005.

Keijzer, Niels ve Bossuyt, Fabienne. Partnership on Paper, Pragmatism on The Ground: The European Union"s Engagement With Civil Society Organisations, Development in Practice, 30/6(2020), 784-794.

Kınay, Sibel. İlköğretim Okulu Yöneticilerinin Yönetsel Etik İlkelere Bağlılık Düzeylerinin Öğretmen Görüşlerine Göre Değerlendirilmesi.(Yüksek Lisans Tezi.), Gazi Üniversitesi Eğitim Bilimleri Enstitüsü Eğitim Yönetimi ve Denetim Bilim Dall, Ankara, 2006.

Kıranlı, Semra - İlğan, Abdurrahman. Eğitim Örgütlerinde Karar Verme Süreçlerinde Etik, Mehmet Akif Ersoy Üniversitesi Eğitim Fakültesi Dergisi, 14 (2007), 150162.

Kırel, Çiğdem. Örgütlerde Etik Davranışlar, Yönetimi ve Bir Uygulama Çalışması, Eskişehir: Anadolu Üniversitesi Yayınları, (2000).

Koçak, Süleyman - Yüksel, Gülçin. Türk Kamu Yönetiminde Etik ve Kamu Görevlileri Etik Kurulu Bilgi Sosyal Bilimler Dergisi, 2 (2010), 73-96.

Kuçuradi, İoanna. Açılış Konuşması. 1. Uluslararası Etik Kongresi Kitabı, Ankara: ODTÜ Felsefe Bölümü, 2001.

Kutlu, Önder. Kahraman, Selçuk \& Dinçer, Selçuk. Demokratik Kamu Politikalarına Sivil Toplum Katkısı: Konya STK Platformu Örneği, Yönetim ve Ekonomi: Celal Bayar Üniversitesi İktisadi ve İdari Bilimler Fakültesi Dergisi, 28/1 (2001), 139-167.

Kurt, Süleyman - Taş, H. Yunus. Sivil Toplum Örgütlerinde Profesyonel ve Gönüllü Çalışma İlişkileri: Tehditler ve Fırsatlar, Hak-İş Uluslararası Emek ve Toplum Dergisi, 4/8 (2015), 199-214.

Küçükoğlu, Mübeyyen. Etik Değerler ve Etiğin Kurumsallaşması, Hukuk ve Íktisat Araştırmaları Dergisi, 4/1 (2012), 177-185.

İbrahimoğlu, Nurettin vd., Relationship Between Culture \& Ethic: A Research in terms of Cultural Diversity, Procedia-Social and Behavioral Sciences, 143 (2014).,1117-1119.

Marshall, Gordon. Sosyoloji Sözlügü (Çev.: Osman Akınhay ve Derya Kömürcü), Ankara: Bilim ve Sanat Yayınları, 1999.

Onbaşı, Funda. Sivil Toplum, İstanbul: L\&M Yayınları, 2005.

Önen, S. Mustafa - Yıldırım, Ali. Kamu Yönetiminde Etik Denetimi: OECD Ülkeleri Örneği, Akademik Yaklaşımlar Dergisi, 5/1 (2014),103-126.

Öner, Şerif. Sivil Toplum Kuruluşlarının Yerel Demokrasi ve Katılım Algılamaları, Çağdaş Yerel Yönetimler Dergisi, 10/2 (2001), 51-67.

Öner, Şerif - Şen, Lütfi Mustafa. Belediye Sivil Toplum İlişkileri: Yasal - Kurumsal Mevcut Durum ve Plan Vizyonu, 3/3(2020), 579-593.

Özdemir, Erkan. Pazarlama Araştırmasında Etik Karar Alma, Ankara Üniversitesi SPF Dergisi, 64 (2009), 119-144. 
Özdemir, Murat. Kamu Yönetiminde Etik, ZKÜ Sosyal Bilimler Dergisi, $4 / 7$ (2008), 179-195.

Özden, Kemal. Sivil Toplum ve Sivil Toplum Kuruluşları, (Ed. Ali Coşkun) Sivil Toplum Kuruluşlarında Yönetim, Ankara: Seçkin, 2008.

Özer, M. Halis. Günümüz İtibariyle Sivil Toplum Kuruluşlarının İktisadi ve Sosyal Fonksiyonları, Elektronik Sosyal Bilimler Dergisi, 7/26 (2008), 86-97.

Özgür, Bünyamin. Kamu Yönetimi Denetçilerinde Etik Kültürün Geliştirilmesi, Denetişim, 5 (2016), 17-32.

Özkal Sayan, İpek. Etik ve Kamu Etiği: Eleștirel Bir Bakıș, Sosyal ve Beşeri Bilimleri Dergisi, 12/2 (2020),147-174.

Özkul, Osman.Demokratik Hakların Gelişmesinde Sivil Toplum Düşüncelerinin Katklları, Emek ve Toplum,6/14 (2017),11-24.

Özlem, Doğan. Günümüzde Felsefe Disiplinleri, İstanbul: İnkılap Kitapevi Yayınları, 1997.

Özler, Derya vd., Teorik Çerçevede Whistleblowing-Etik İlişkisi, Eskişehir Osmangazi Üniversitesi Sosyal Bilimler Dergisi, 11/2 (2010), 169-194.

Özsalmanlı Yıldız, Ayşe - Pank, Çiğdem. Kamu Yönetiminde Etik Açısından Algılama Yönetimi ve Önemi, Hukuk ve İktisat Araştırmaları Dergisi, 5/2 (2013), 47-61.

Pehlivan, İnayet. Yönetsel, Mesleki ve Örgütsel Etik, Ankara: Önder Matbaacılık, 1998.

Pieper, Annemarie. Etiğe Giriş. (Çev. Veysel Atayman ve Gönül Sezer), İstanbul: Ayrıntı Yayınları, 2009.

Rousseau, J.J. Toplum sözleşmesi. (A. Erenuluğ, Çev.). Ankara: Öteki Yayınevi. (1999).

Sabuncuoğlu, Zeyyat - Tüz, Melek. Örgütsel Psikoloji, 3.Basım, Bursa: Alfa Basım Yayım Dağıtım, 1998.

Svara, James H. The Ethics Primer for Public Administrators in Government and Nonprofit Organization, Arizona: Jones and Bartlett Publishers, 2007.

Şan, Mustafa Kemal. - Bilen, Mahmut. "Yoksulluk Sorunuyla Mücadelede Bir Strateji Olarak Sivil Toplum Kuruluşları: Deniz Feneri Örneği. I. Ulusal Sivil Toplum Kuruluşları Kongresi, Küresel Demokrasinin Gelişmesi ve Katılım Sağlanması Açısından Sivil Toplum Kuruluştan Bildiriler Kitabı, 197-212, 2004.

Taner, Bahar - Elgün, Rıza Feridun. Çalışanların Etik İklim Algılarının Örgütsel Bağlılık Üzerine Etkileri: İlaç Sektöründe Bir Uygulama. Çukurova Üniversitesi Sosyal Bilimler Enstitüsü Dergisi, 24/1 (2015), 99-114.

Talas, Mutafa. Sivil Toplum Kuruluşları ve Türkiye Perspektif, TÜBAR-XXIX Niğde Üniversitesi Eğitim Fakültesi Bölümü, (2011), 388-401

Tekeli, İlhan. Kuramsal Yaklaşımlar, Sivil Toplum Kuruluşları ve Yasalar EtikDeprem, İstanbul: Türkiye Ekonomik ve Toplumsal Tarih Vakfı Yayını, 2000.

Teegen, Hildy vd., The Importance of Nongovernmental Organizations (Ngos) in Global Governance and Value Creation: An International Business Research Agenda, Journal of International Business Studies, 35 (2004), 463-483. 
Tocqueville, Alexis. De. Amerika'da demokrasi, (İ. Sezal ve F. Dilber, Çev), Ankara: Yetkin Yayınları. (1994).

Töre, Esra. The Effect Of Organizational Climate And Organizational Commitment On Unethical Behavior At Work (Yayınlanmamış Yüksek Lisans Tezi), Marmara Üniversitesi Sosyal Bilimler Enstitüsü, İstanbul, 2006.

Tuncay, Tarık. Sivil Toplum Örgütlerinin İşlevleri, Tarık Tuncay (Ed.). Sivil Toplum Örgütleri içinde (42-59), Erzurum: Atatürk Üniversitesi Açıöğretim Fakültesi Yayını, 2019.

Türegün, Nida. Etik Algısının Kültürel Boyutlar Açısından Değerlendirilmesi: MINT Ülkelerindeki Öğrenciler Üzerine Bir Çalışma, Sosyal Bilimler Araştırma Dergisi, 8/3 (2019), 102-119.

Uluç, A. Vahap. Birey ve Sivil Toplum İlişkisi Çerçevesinde Türkiye'de Demokrasi Sorunu. Mukaddime, 0/6 (2012), 1-19.

Uluğ, Feyzi. Yönetim ve Etik. (Ed. F. Uluğ ve diğerleri), Kamu Etiği Sempozyum Bildirileri 1, 1/3-15, Ankara: TODAIE, 2009.

Usta, Aydın. Kuramdan Uygulamaya Kamu Yönetiminde Etik ve Ahlâk. Kahramanmaraş Sütçü Imam Üniversitesi İktisadi ve İdari Bilimler Fakültesi Dergisi, 1/2 (2011), 39-50.

Uzun, Ruhdan. İletişim Etiği: Sorunlar ve Sorumluluklar. Ankara: Dipnot Yayınları, 2009.

Uzun, Yaşar. İç Denetim ve Dış Denetim Faaliyeti Olarak Etiği Denetlemede İzlenebilecek Yaklaşımlar, Ombudsman Akademik, 6/11 (2019), 73-111.

Uzun, Yaşar. Kamu Sektörü Denetiminde Yeni Bir Bakış: Etik Denetimi, Muhasebe Bilim Dünyası Dergisi, 20/1 (2018), 144-161.

Uzun, Yaşar. Kamu İdarelerinde Etik Yönetim Altyapısı ve Değerlendirilmesi, Ombudsman Akademik, 3/6 (2017), 107-141.

Velioğlu, Mehmet. Sivil Toplum Kuruluşlarının Demokrasi Üzerindeki Etkileri, (Yüksek Lisans Tezi) Kırıkkale Üniversitesi Sosyal Bilimler Enstitüsü Kamu Yönetimi Ana Bilim Dalı, Kırıkkale, 2009.

White, Gorge. CivilSociety, Demokratization and Development: Clearing the Antonikal Ground, Demokratization, (1994).

Yaman, Adem. İç Denetçinin Yeni Rolü; Etik Liderlik, Denetişim, 5 (2016), 9-16.

Yavuz, Cavit. Ve Kaynar, İbrahim. Kamuoyu Oluşumunda Stratejik Bir Araç Olarak Sivil Toplum Kuruluşları, Manas Sosyal Araştırmalar Dergisi, 42 (2015), 183196.

Yeşildal, Ali. Sivil Toplum ve Yerel Yönetimlerde Katılım: Yönetişim Temelli Bir Yaklaşım, Sosyal Bilimler Metinleri,20/2 (2020),31-44.

Yıldırım, Gülay. ve Kadıoğlu, Selim. Etik ve Tıp Etiği Temel Kavramları, C.Ü. Tıp Fakültesi Dergisi 29/2 (2007), 75-84.

Yıldırım, Murat. Sivil Toplum ve Devlet, C.Ü. Sosyal Bilimler Dergisi, 27/2 (2003), 226-242. 